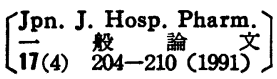

\title{
直接打錠法による割線入り錠剤の分割性
}

\author{
伊東明彦, 荒木由美子, 杉原正泰 \\ 東京女子医科大学病院薬剤部
}

\section{Dividing Property of Scored Tablet Produced by Direct Compression Method}

\author{
Akihiko Ito, Yumiko ARaki, Masayasu Sugihara \\ Hospital Pharmacy, Tokyo Women's Medical College†
}

(Received December 12, 1990)

\begin{abstract}
Dividing property was investigated in scored tablets compressed by direct compression method. For the excipients, lactose (SL), corn starch (CS), synthetic aluminum silicate (SAS), hydroxy propyl starch (HPS), microcrystalline cellulose (MCC) and Perfiller were used. Dividing strength of tablet was in the order MCC tablet $>$ Perfiller ${ }^{\oplus}$ tablet $>$ SAS tablet $>$ SL, HPS and CS tablets. The dividing strength of SL-MCC and SL-Perfiller mixture tablets increased with an increase of the mixing rate. But the dividing strength of SL-CS mixture tablet was unchanged.

Weight variation of tablet halves was affected by compaction profiles of excipients alone. MCC, SAS and Perfiller ${ }^{\circledR}$ showed straight compaction profiles, these tablets had little weight variation of tablet halves. But in the case of SL-CS, SL-MCC and SL-Perfiller ${ }^{\otimes}$ mixture, no difference of compaction profiles was shown and SL-MCC mixture tablet alone decreased the weight variation of tablet halves of SL tablet. Then a correlation between dividing strength of tablet and weight variation of tablet halves was found in SL-MCC and SL-Perfiller ${ }^{\circledR}$ mixture tablets.
\end{abstract}

Keywords — scored tablet; weight variation; dividing strength; compaction profile; excipient; direct compression method

著者らはこれまで割線入り錠剤の分割性につい て湿式造粒した顆粒を用いて検討した ${ }^{1,2)}$. 割線入 り錠剤の分割性は圧縮充媜構造の影響を受けると 考えられた. 圧縮充填構造は粉粒体の物性によっ て異なり，圧縮充填性の相違によって影響される と考えられる. 湿式造粒した顆粒を用いた場合, 二次粒子特性としての圧縮充媜挙動を示すため圧 縮充媜構造への影響は種々の要因を含んで複雑化

†東京都新宿区河田町8-1；8-1, Kawada-cho, Shinjuku-ku, Tokyo, 162 Japan
してくる.

そこで，圧縮充填性の影響を明らかにするた め, 一次粒子特性の圧縮挙動として考えられる種 々の賦形剤を用いて直接打錠法により割線入り錠 剤を製し，その分割性について検討した。さら に, 混合粉体についても同様の検討を行った.

\section{実 験 の 部}

\section{1. 試料}

粉末乳糖 SL (日局), ヒドロキシプロピルスタ 
ーチ HPS (フロイント産業, HPS-101), 合成ケ イ酸アルミニウムSAS (日局)，コーンスターチ $\mathrm{CS}$ (日局), パーフィラー®（フロイント産業, HPSを主体とする微細粒 $\left.{ }^{3}\right)$ および結晶セルロ ース MCC (旭化成, 商品名アビセル PH101) を 100 メッシュで穊過 したものを用いた．打錠にあ たっては滑沢剤として0.5\%(w/w) のステアリン 酸マグネシウムを添加した。

\section{2. 錠削の調製}

各試料 $300 \mathrm{mg}$ を秤量し, $\mathrm{KBr}$ 錠剂成形器に て成形圧約 $700 \mathrm{~kg} / \mathrm{cm}^{2}$ で 1 分間圧を加えて成形 した. 割線の溝の深さは錠剤の厚さの約 $10 \%$ と た.

\section{3. 分割方法および錠戍の分割時の強度測定}

レオメーター (サン科学)を用いて, 割線に沿 って分割し，そのときの圧力を分割時の強度とし た。

\section{4. 分割後の重典の変動の測定}

前報1の方法と同様に行った.

\section{5. 試料粉体の圧密過程の解析}

荒川4) の報告に基づき各試料についてタッピン グ圧縮を行い, Cooper の式を用いて圧密過程を 体積減少率 $\left(\mathrm{V}_{0}-\mathrm{V}_{\mathrm{n}} / \mathrm{V}_{0}-\mathrm{V}_{\infty}\right)$ とタッピング回数
の対数 $(\log N)$ の関係で示した.

$$
\mathrm{V}_{0}-\mathrm{V}_{\mathrm{n}} / \mathrm{V}_{0}-\mathrm{V}_{\infty}=\mathrm{a}_{1} \mathrm{e}^{\mathrm{k} 1 \mathrm{n}}+\mathrm{a}_{2} \mathrm{e}^{\mathrm{k} 2 \mathrm{n}}
$$

ここで， $\mathrm{V}_{0}, \mathrm{~V}_{\infty}$ はそれぞれ初期および最密充 媜体積, $\mathrm{V}_{\mathrm{n}}$ は $\mathrm{n}$ 回タッピングした時の充媜体積 であり， $\mathrm{V}_{0}-\mathrm{V}_{\mathrm{n}} / \mathrm{V}_{0}-\mathrm{V}_{\infty}$ はタッピング圧縮によ る体積減少率になる。 $\mathrm{a}_{1}, \mathrm{a}_{2}, \mathrm{k}_{1}$ および $\mathbf{k}_{2}$ は定 数である.

\section{結果および考察}

\section{1. 各試料錠剤の分割性}

Fig. 1 亿各錠剤の分割時の強度を示す $\mathrm{MCC}$ が最も大きく, ついでパーフィラー ${ }^{\circledR}, \mathrm{SAS}$ の順 で，SL，CS および HPS がほぼ同様の小さな值 を示した. 分割強度の差は各粉体の圧縮成形時の 圧密化傾向の違いによる内部構造の相違によるも のと考えられる.

Fig. 2 に各試料錠剂の分割重量の変動を示 す. SAS, MCC およびパーフィラー®が $6.2 \sim 7.0$ の小さな CV 值を示し, SL, CS および HPS は 10.3〜11.2の大きな CV 值であった。この均一な 分割性の違いは各粉体の圧縮充填性の相違と考え られる.そこで各試料の圧密過程を Fig. 3 に示 す. 圧密過程は試料間に明らかな違いが認められ

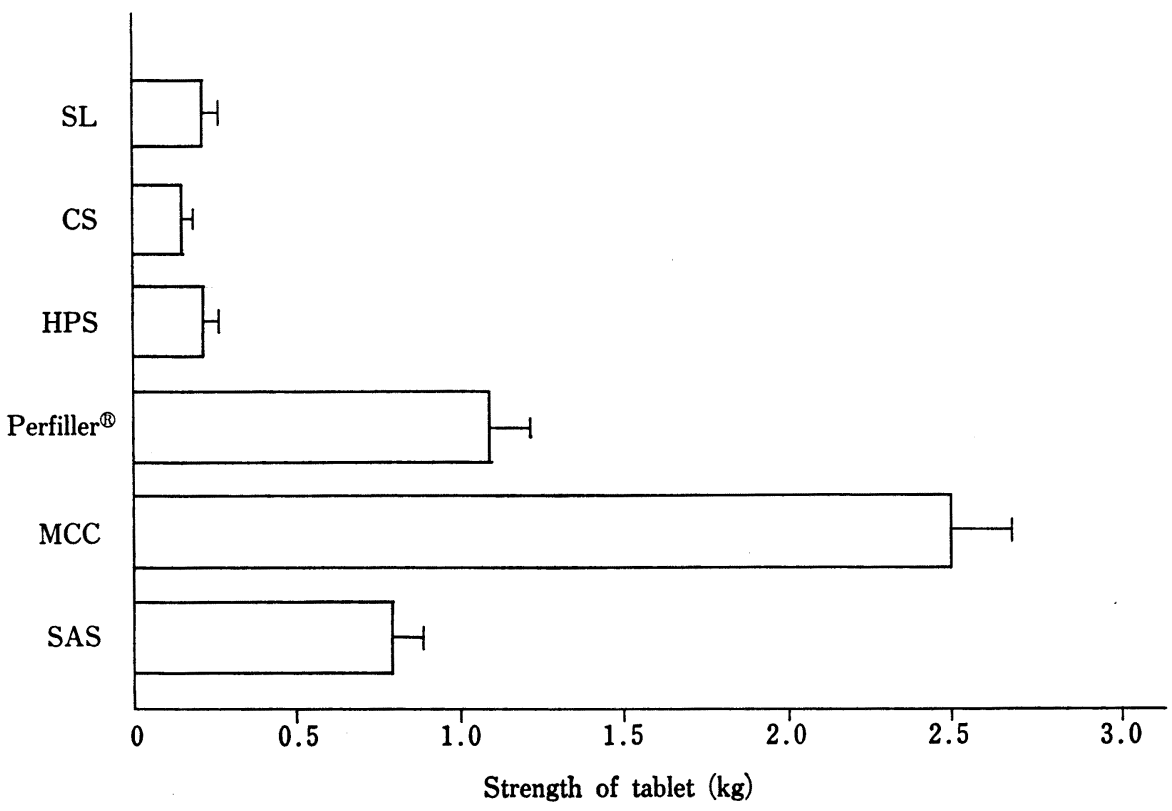

Fig. 1. Strength of Excipients Tablets 


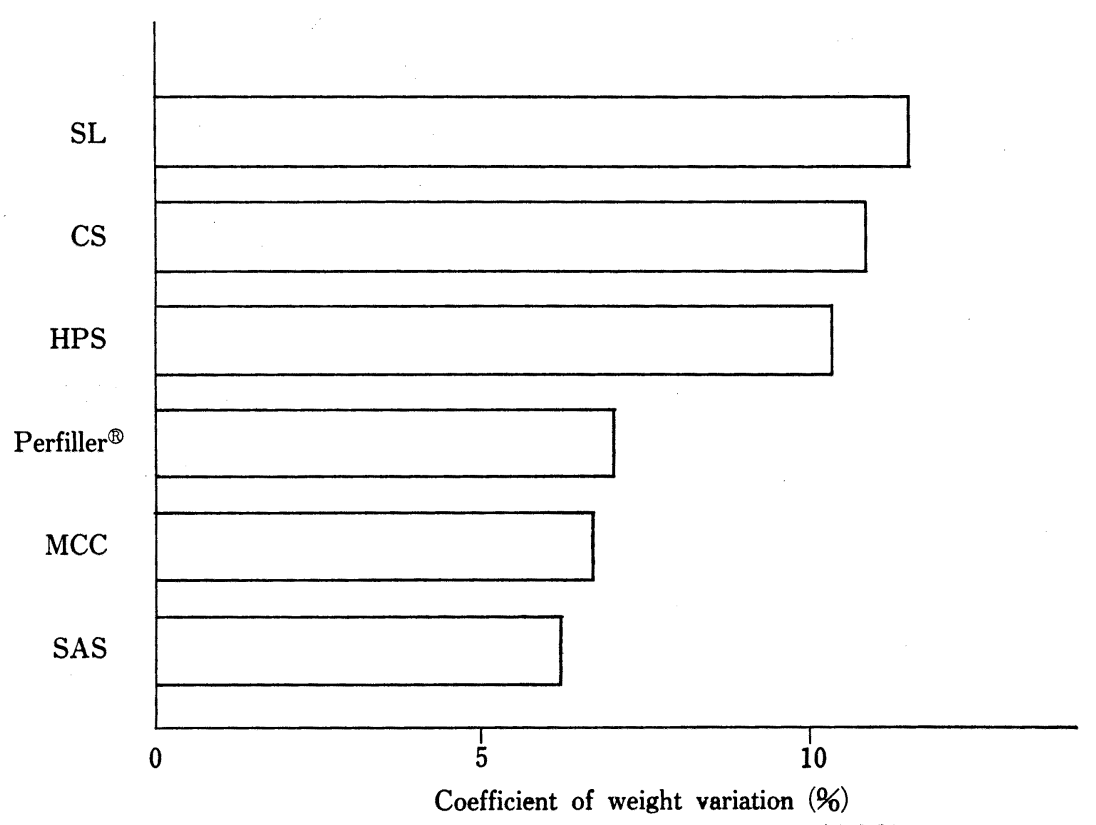

Fig. 2. Weight Variation of Divided Excipients Tablets
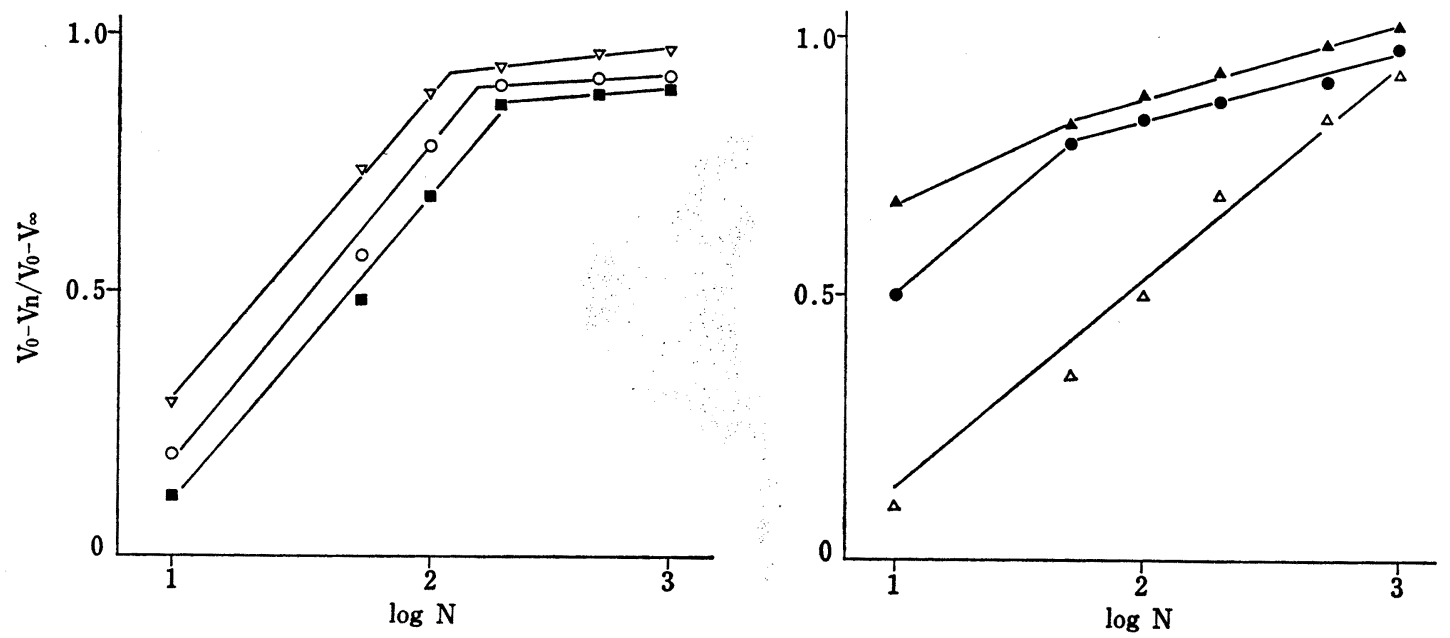

Fig. 3. Compaction Profiles of Excipients by Cooper's Equation

$\nabla: \mathrm{SL}, \circ: \mathrm{CS}, \boldsymbol{\square}: \mathrm{HPS} \quad \triangle: \mathrm{SAS}, \bullet: \mathrm{MCC}, \boldsymbol{\Delta}:$ Perfiller $\circledast$

た. SL, CS および HPS はいずれもある点で明 らかな屈曲点がみられ，SAS, MCCおよび HPS は比較的直線に近い圧密過程を示した．荒川苂の 考えに基づけば，この結果から SL，CS および HPS は初期充填で軟凝集状態を生じており, SAS, MCC 抽よ゙パーフィラー『は比較的よく分 散しているといえる.この圧密過程の違いを模式
的に示すと Fig. 4 のように示すことができる.

A）は充填初期には粒子間の付着, 凝集により 凝集構造を示しており，加圧によって凝集構造が 破壊されて充填される．そしてさらに加圧される ことにより密充填状態になる挙動を示す場合で, 屈曲点の発生した SL，CS および HPS がこの場 合にあたり, 凝集構造の破壊が屈曲点発生の理由 
A)
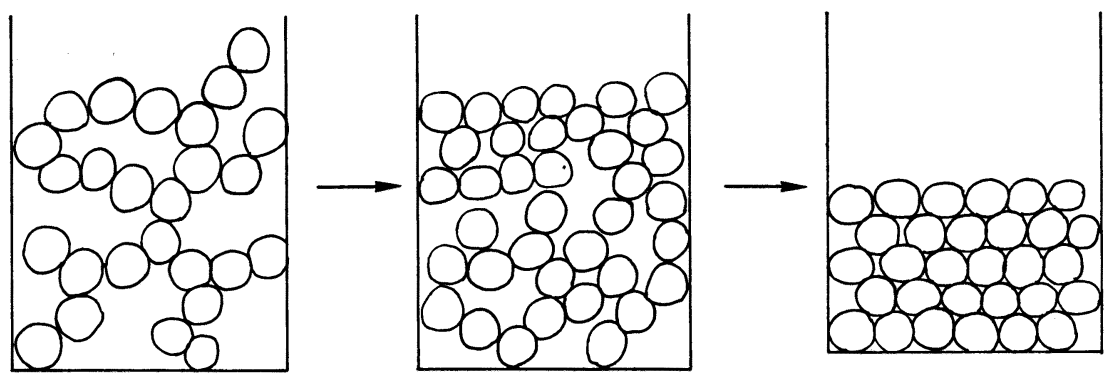

B)
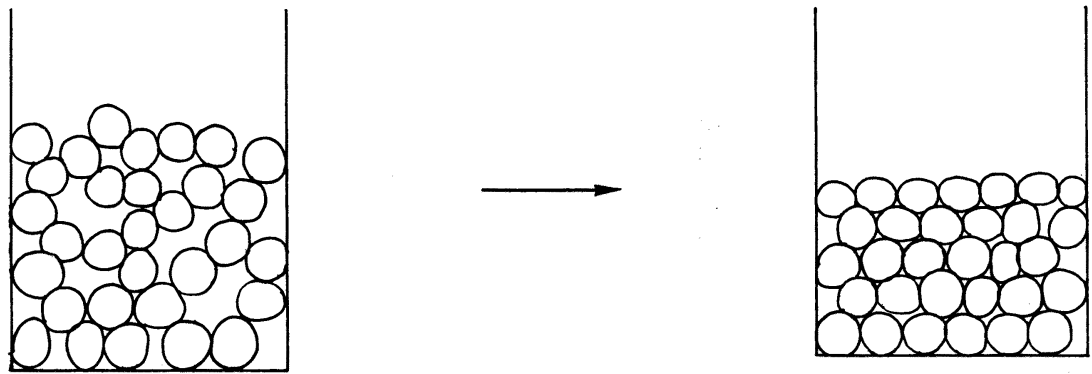

Fig. 4. Model of Compaction Profiles

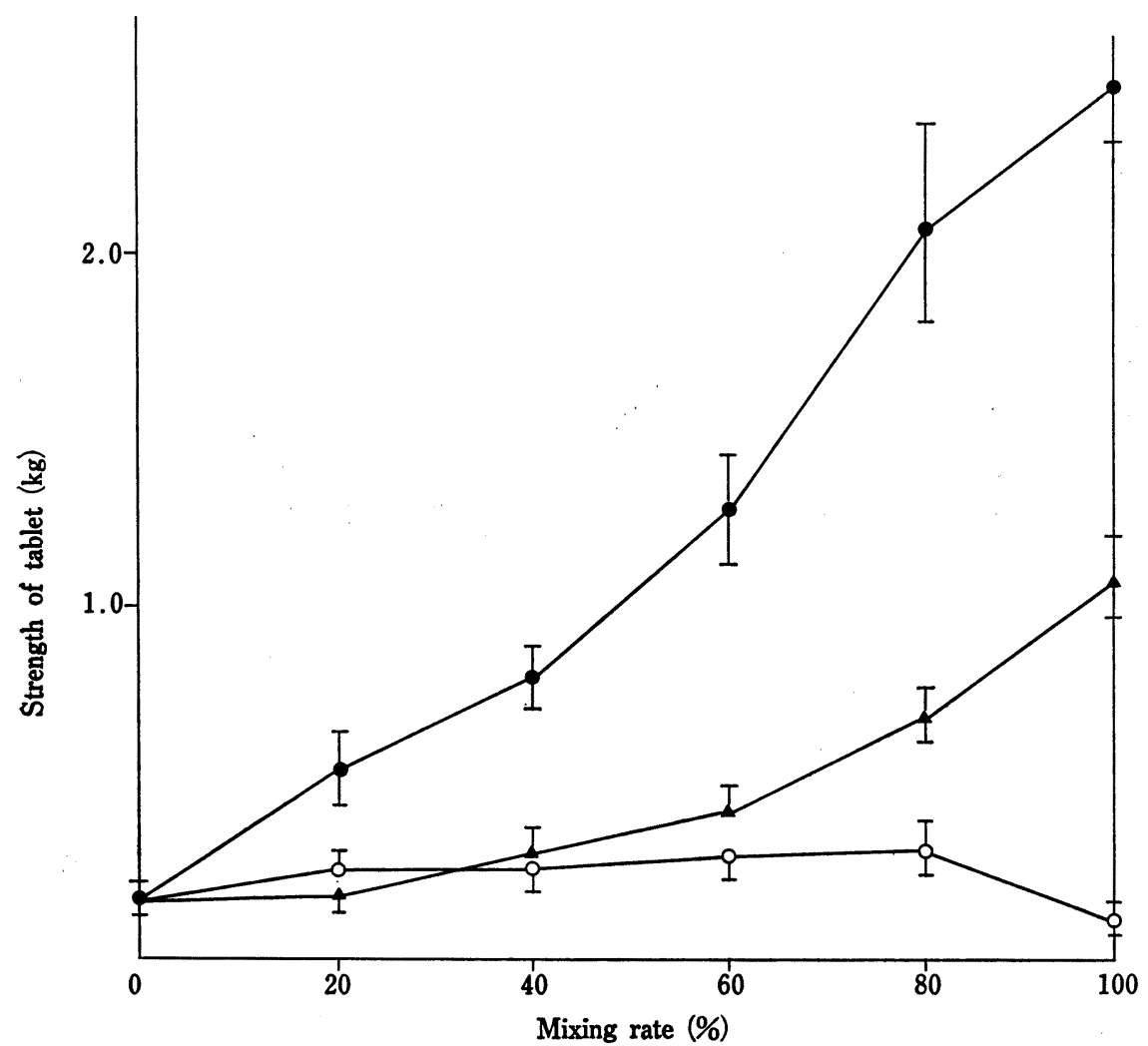

Fig. 5. Change of Strength of Tablet with Mixing Rate of Other Excipients to Lactose $\bullet:$ MCC, $O$ : CS, $\Delta$ : Perfiller $\circledast$ 
であると考える，一方，B）は個々の粒子が比較 的よく分散しており，加圧によってほぼ一様に圧 密が進行する挙動を示す場合で, 直線的圧密過程 を示した SAS, MCCおよびパーフィラー®がこ の場合にあたると考えられる．このように分割重 量の変動において大きな CV 值を示した SL, CS および HPS と比較的小さな值を示した SAS, MCC およびパーフィラー®とでは圧密過程が明 らかに異なり, 圧密過程の違いが均一な分割性に 影響をおよぼすことが示唆された，SL，CS およ び HPS は屈曲点発生の理由である凝集構造の破 壊により構造不整面が発生し，そのため大きな CV 值を示したと考えられる. また， SAS, MCC およびパーフィラー®はその圧密過程が示すよう にほぼ一様に圧密となるため比較的均一な密度分 布を示したと考えられる。

\section{2. 混合粉体の混合比率之錠冎刂分割性}

分割重量の変動に括いて大きな $\mathrm{CV}$ 值を示した
$\mathrm{SL}$ に同様に大きな $\mathrm{CV}$ 值を示した CS，そして 小さな CV 值を示した MCC およびパーフィラ 一『を混合した各混合粉体を用いて割線入り錠剤 を製しそその分割性について検討した．Fig. 5 に 各混合粉体の混合比率と分割時の強度の関係を示 す.

MCC およびパーフィラー®の混合系は混合比 率が大きくなるにしたがって分割時の強度は大き くなる傾向を示し，MCC 混合系が最も大きく変 化した。 そして CS 混合系ではほとんど变化は認 められなかった。

Fig. 6 に各混合粉体の混合比率と分割重 量の 変動の関係を示す. いずれの混合系も混合比率が 大きくなるにしたがって CV 值は低下する傾向を 示した。しかし CSおよびパーフィラー『混合系 は SL 単独の CV 值よりも大きな值を示し, MCC 混合系のみが SL 単独の CV 值を低下させた. それぞれの混合系について各混合比率で混合した

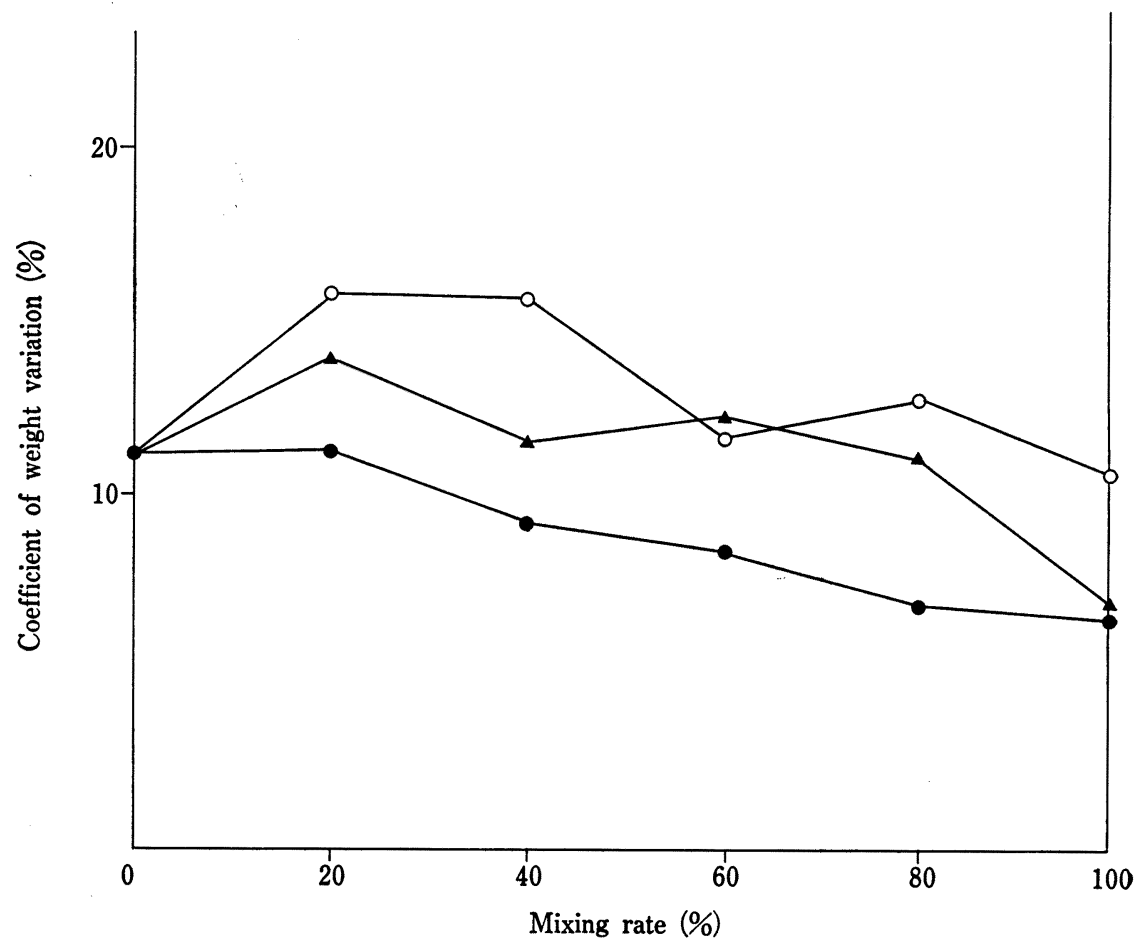

Fig. 6. Change of Weight Variation of Divided Tablets with Mixing Rate of Other Excipients to Lactose

- : MCC, O : CS, $\Delta$ : Perfiller ${ }^{\circledR}$ 

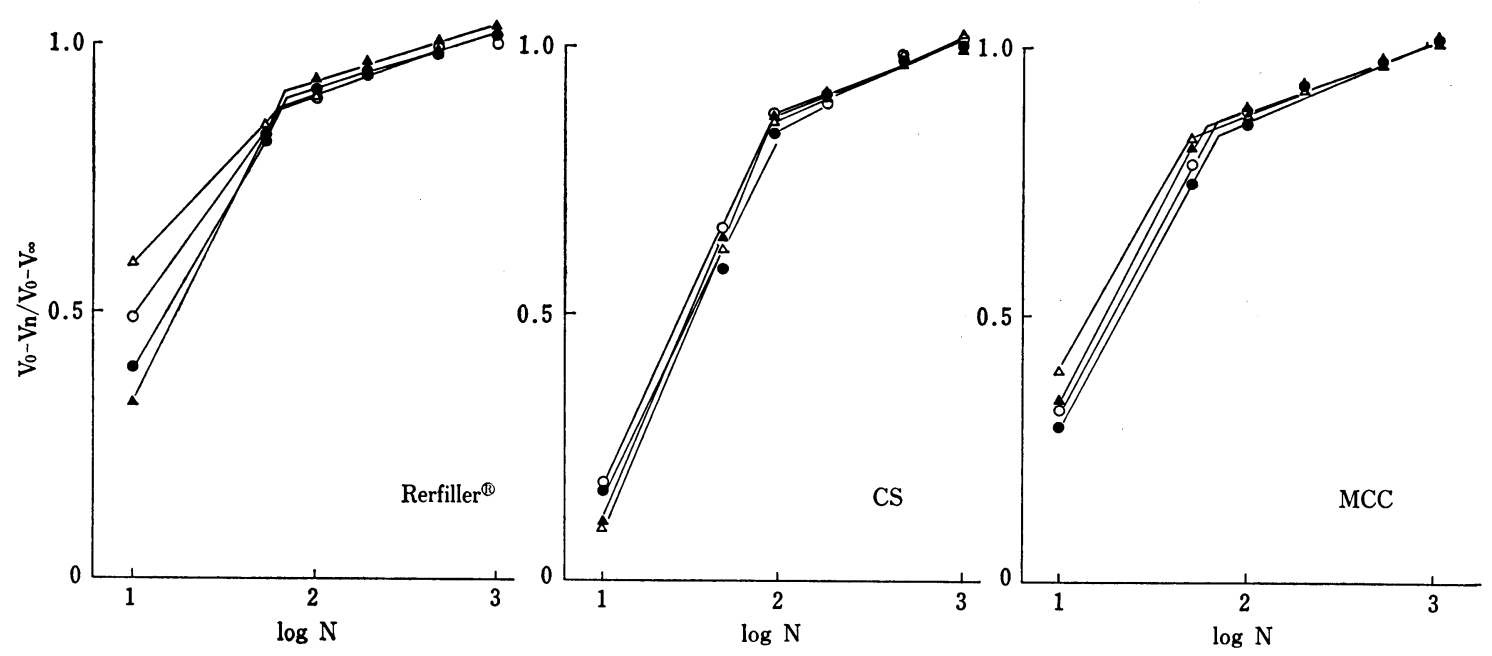

Fig. 7. Compaction Profiles by Cooper's Equation with Mixing Rate of Other Excipients to Lactose - : 20\%, ०: $40 \%, \triangle: 60 \%, \triangle: 80 \%$

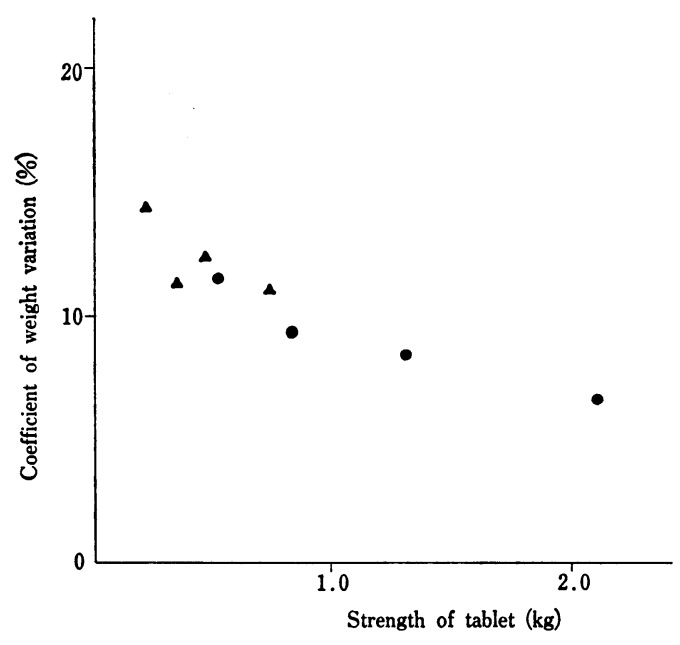

Fig. 8. Relationship between Weight Variation of Divided Tablets and Strength of Tablet

$\Delta$ : SL-Perfiller ${ }^{\circledR}, \bullet:$ SL-MCC

粉体の圧密過程を Fig. 7 に示す.

パーフィラー『混合系で混合比率の变化に伴っ て若干圧密過程の変化が認められたが，CS およ び MCC 混合系はほとんど変化は認められなかっ た. そしていずれの混合系の場合も明らかに屈曲 点の発生が見られた.このようにいずれの混合系 の場合も凝集構造からの圧密挙動であり, 混合系 の場合には均一な分割性の相違は圧密過程の違い
としては考えられないと思われた. 混合系の場合 は粉体層内に SL 粒子と混合された CS, MCC お。 よびパーフィラー®の各粒子が存在しており, そ れぞれの接触状態や接触力の相違が考えられる. したがって単一系の場合と違って不連続な充媜 構造を生じ, それぞれの充填構造を局部的に破壊 するような状態であると考えられる.そのため CS およびパーフィラー®の混合系は SL 単独の 值を低下させず，大きい值からの低下傾向を示し たと考える. MCC 混合系の場合は MCC が非常 に成形性が良く, 他の試料に比べて強度がかなり 大きいこと，また気賀沢ら ${ }^{6)}$ が SL と MCC の混 合系で SL の多い試料孚ど内部構造が不均一で, MCC が多いほど均一であると報告していること から MCC 粒子のつくるネットワークが支配的に なっていると考えられる. そのため MCC 混合系 はSL 単独の均一な分割性を改善させたと考えら れる。

各混合系の試料錠剂のらち, 分割時の強度変化 が認められた MCC およびパーフィラー®混合系 について分割時の強度と分割重量の変動との関係 を検討した. その結果, Fig. 8 に示すような関 係がみられ, 分割時の強度と $\mathrm{CV}$ 值の対数との間 に高い相関性（相関係数， $\mathrm{r}=0.960, \mathrm{p}<0.01$ ) が認められた.このことからこれらの混合系につ 
いては分割時の強度の大きいほらが比較的均一な 分割性を示すように推測された。

\section{参考文献}

1）伊東明彦, 小林由美子, 杉原正泰, 病院薬学, 15, 5-10 (1989).

2) 伊東明彦, 小林由美子, 杉原正泰, 病院薬学,
15, $11-16$ (1989).

3）フロイント産業資料

4）荒川正文, “粉体成形ハンドブック”，日本工業 新聞社, 東京, 1987, p.75.

5）荒川正文，“粉体成形ハンドブック”，日本工業 新聞社, 東京, 1987, p. 76-77.

6）気賀沢和雄, 飯村秀樹, 谷崎 明, 杉村英昭, 清 水弘明, 薬学雑誌, 95, 769-773 (1975). 